\title{
Increased CD56 bright NK cells in HIV-HCV co-infection and HCV mono-infection are associated with distinctive alterations of their phenotype
}

Suvercha Bhardwaj ${ }^{1}$, Fareed Ahmad ${ }^{2}$, Heiner Wedemeyer ${ }^{3,7}$, Marcus Cornberg ${ }^{3,7}$, Julian Schulze zur Wiesch $^{4,7}$, Jan van Lunzen ${ }^{6}$, Shiv K. Sarin ${ }^{1 *}$, Reinhold E. Schmidt ${ }^{2,7}$ and Dirk Meyer-Olson ${ }^{2,5^{*}}$

\begin{abstract}
Background: HIV-HCV co-infection is associated with accelerated progression to hepatic fibrosis, cirrhosis and hepatocellular carcinoma than HCV mono-infection. The contribution of innate immunity during HIV-HCV coinfection has been a relatively under-investigated area. Natural killer (NK) cells are pivotal sentinels of innate immunity against viruses and tumour cells. In this study we evaluated the effect of HIV-HCV co-infection on peripheral blood NK cell subsets with emphasis on the phenotype of CD56 ${ }^{\text {bright }}$ NK cells.
\end{abstract}

Methods: Sixty patients were included in the study; HIV mono-infected $(n=12)$, HCV mono-infected $(n=15)$, HCV-HIV co-infected $(n=21)$ and healthy controls $(n=16)$. PBMCs were isolated and immunophenotyping of NK cells was performed by flowcytometry.

Results: We observed an expansion of CD56 $6^{\text {bright }}$ NK cell subset in HIV-HCV co-infection as compared to healthy controls and HIV mono-infected group. All the infected groups had an upregulated expression of the activating receptor NKG2D on CD56 bright NK cells in comparison to healthy controls while not differing amongst themselves. The expression of NKp46 in HIV-HCV co-infected group was significantly upregulated as compared to both HIV as well as HCV mono-infections while NKp30 expression in the HIV-HCV co-infected group significantly differed as compared to HIV mono-infection. The CD56 bright NK cell subset was activated in HIV-HCV co-infection as assessed by the expression of CD69 as compared to healthy controls but was significantly downregulated in comparison to HIV monoinfection. CD95 expression on CD56 bright $\mathrm{NK}$ cells followed the same pattern where there was an increased expression of CD95 in HIV mono-infection and HIV-HCV co-infection as compared to healthy controls. In contrast to CD69 expression, CD95 expression in HCV mono-infection was decreased when compared to HIV mono-infection and HIV-HCV cOinfection. Finally, expression of CXCR3 on CD56 bright NK cells was increased in HIV-HCV co-infection in comparison to HIV mono-infection while remaining similar to HCV mono-infection.

Conclusion: Thus, HIV-HCV co-infection is able to modulate the phenotype of CD56 bright NK cell subset in a unique way such that NKp46 and CXCR3 expressions are distinct for co-infection while both mono-infections have an additive effect on CD56 bright, CD69 with CD95 expressions. HCV mono-infection has a dominant effect on NKp30 expression while NKG2D and CD127 expressions remained same in all the groups.

\footnotetext{
* Correspondence: dirk.meyer-olson@fachklinik-bad-pyrmont.de; shivsarin@ gmail.com

${ }^{1}$ Institute of Liver and Billiary Sciences, New Delhi, India

${ }^{2}$ Klinik für Immunologie und Rheumatologie, Medizinische Hochschule

Hannover, Hannover, Germany

Full list of author information is available at the end of the article
} 


\section{Background}

NK cells are effector cells of the innate immune system, capable of destroying virus-infected and tumour cells without prior sensitization $[1,2]$. The majority of human NK cells in peripheral blood are $\mathrm{CD} 56^{\mathrm{dim}} \mathrm{CD} 16^{+}$cells whereas CD $56^{\text {bright }} \mathrm{CD} 16^{+/-}$cells only constitute approximately $10 \%$ of the peripheral blood NK cell pool [3]. In addition, CD56 ${ }^{\text {bright }}$ NK cells have high surface density expression of type II membrane glycoprotein CD94, L-Selectin 62L, CD127 and lymph node homing receptor CCR7 but low expression of the low affinity IgG-Fc receptor III (CD16), killer cell immunoglobulin-like receptors (KIRs) and cytotoxic molecules such as perforin and granzyme B [4]. Thus, NK cell subsets seem to perform distinct roles in the immune response. CD56 ${ }^{\text {bright }} \mathrm{NK}$ cells have more regulatory functions by means of cytokine production while CD $56^{\mathrm{dim}} \mathrm{NK}$ cells are primarily cytolytic in function but produce significant amounts of cytokines when their activating receptors are engaged [5]. This distinction is however not absolute [6].

The chemokine receptor repertoire also differ among the NK cell subsets with the expression of CXCR3 at a much stronger density on CD56 ${ }^{\text {bright }}$ subset than CD56 ${ }^{\text {dim }}$ cells, while the latter express CXCR1 and CX3CR1 exclusively $[5,7]$. The differential repertoires of chemokine receptors and adhesion molecules endow NK cell subsets with divergent migratory properties: the CD56 ${ }^{\text {bright }}$ subset preferentially homes to secondary lymphoid organs whereas the CD56 ${ }^{\mathrm{dim}}$ cells home to acute inflammatory sites $[5,7]$.

Persistent infections by HCV and HIV present unique challenges to the immune system as they result in highly chronic viral persistence which lasts indefinitely without antiviral treatment [8]. In HIV infection, several studies have shown functional impairment in NK cell cytokine secretion and cytotoxicity. Both acute and chronic untreated HIV infection is associated with alterations in NK cell subset distribution, with partial loss of $\mathrm{CD}_{56}{ }^{+} \mathrm{CD} 16^{+}$cells and expansion of $\mathrm{CD}^{-} 6^{-} \mathrm{CD} 16^{+} \mathrm{NK}$ cells having impaired cytolytic function, increased activation markers and decreased cytokine production $[9,10]$. Similarly, HCV viral persistence has also been shown to be associated with defective NK cell responses in vivo both in the periphery and in the liver [7, 11]. NK cell function was rescued after successful IFN- $\alpha$ therapy in chronically HCV infected patients [12].

HIV infection is not only associated with changes in NK cell subpopulation but also with marked alterations in NK cell surface receptor expression and loss of function [13]. In HIV viremic patients, there is an overall decrease in surface receptor density of NKp46 and NKp30 found on freshly isolated NK cells and dysfunction in NKp44 de novo expression upon stimulation in vitro resulting in an NCR dull phenotype [14]. The proportion of NKp46 and NKp30 expressing CD56 ${ }^{\mathrm{dim}}$ NK cells and their cytolytic activity was shown to decrease with disease progression [15].

Contrary to HIV infection, there is no consensus on NCR expression during HCV infection. There are reports that show increased proportions and density of NCRs including NKG2C, NKp44, NKp30 and NKp46 [16, 17] while the earlier reports of decreased expression of NKp46 have not been subsequently confirmed [7]. In addition, couple of recent studies have suggested that $\mathrm{HCV}$ infected cells may selectively down regulate NKp30 and impair NK cell function by this mechanism $[14,18,19]$.

Nearly all NK cells express NKG2D which is considered a potent activating receptor [20] that has the ability to trigger cytotoxicity and at the same time capable of overriding signals provided by other inhibitory receptors. Similar to other NCRs, there is conflicting evidence with respect to NKG2D expression which has been reported from being up-regulated or down-regulated to being unchanged during chronic HCV infection [16, 21].

A number of studies have revealed $\mathrm{CD} 56^{\text {bright }}$ and CD56 ${ }^{\text {dim }}$ NK cells as separate NK cell subsets rather than a homogenous population having unique roles in the innate immune response [7]. By virtue of their ability to produce different cytokines, CD56 ${ }^{\text {bright }}$ NK cells might play an important role in early immune responses as well as in shaping of the adaptive response [5]. Not much is known about the impact of HIV and HCV co-infection on CD56 $6^{\text {bright }} \mathrm{NK}$ cells. In the current study, we therefore investigated the phenotype of CD56 ${ }^{\text {bright }} \mathrm{NK}$ cells in HIV-HCV co-infected subjects and compared these with HCV and HIV monoinfected patients as well as with healthy controls. We found that HIV-HCV co-infection is able to modulate the phenotype of CD56 ${ }^{\text {bright }} \mathrm{NK}$ cells in a complex way.

\section{Results}

Frequency of CD56 ${ }^{\text {bright }}$ NK cells

We defined NK cells as CD3 ${ }^{-} \mathrm{CD} 14^{-} \mathrm{CD} 19^{-}$lymphocytes expressing either CD16 or CD56 or both as described previously [10]. Utilizing CD56 and CD16 we defined CD56 ${ }^{\text {bright }}$ NK cell population in peripheral blood as shown in Fig. 1a. The percentage of CD56 ${ }^{\text {bright }} \mathrm{CD} 16^{+/-}$NK cells in HIV and $\mathrm{HCV}$ mono-infections did not differ significantly as compared to the healthy controls. On the other hand HIVHCV co-infection had significant upregulation of CD56 ${ }^{\text {bright }} \mathrm{CD} 16^{+/-}$NK cells as compared to healthy controls. As compared to mono-infections HIV-HCV co-infection had an upregulated expression of $\mathrm{CD} 56^{\text {bright }} \mathrm{CD} 16^{+/-} \mathrm{NK}$ cells than HIV mono-infection only. Although HCV mono-infection showed a trend towards increased CD56 ${ }^{\text {bright }} \mathrm{CD} 16^{+/-}$NK cells, only HIV-HCV co-infection resulted in an increase that was significantly different from both healthy controls and HIV mono-infection (Fig. 1b). The log percentage of CD56 $6^{\text {bright }}$ NK cells expressing 

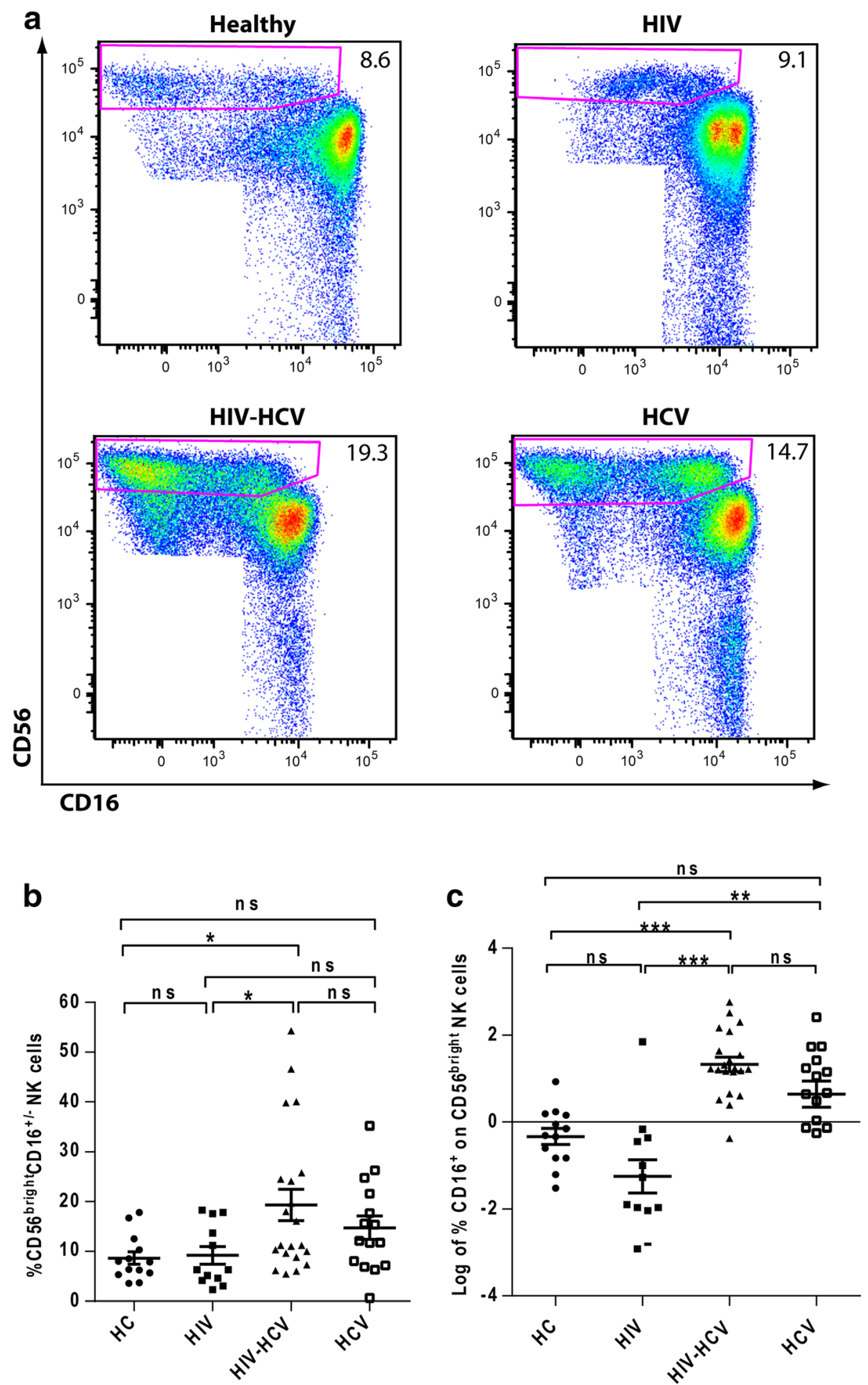

Fig. 1 Increased CD56 ${ }^{\text {bright }} \mathrm{CD} 16^{+/-} \mathrm{NK}$ cells in HIV-HCV co-infection. a Representative gating scheme for identification of CD56 $6^{\text {bright }} \mathrm{CD} 16^{+/-} \mathrm{NK}$ cells. b Comparison of percentage of the CD56 bright $\mathrm{NK}$ cell subpopulation in control subjects $(n=13)$, HIV seropositive $(n=12)$, HIV-HCV co-infected $(n=21)$ and HCV mono-infected individuals $(n=15)$ on $\mathrm{CD} 56^{\text {bright }} \mathrm{CD} 6^{+/-} \mathrm{NK}$ cells. (c) Comparison of log percentage of the CD56 bright $\mathrm{NK}$ cells expressing CD16 in control subjects $(n=13)$, HIV seropositive $(n=12)$, HIV-HCV co-infected $(n=21)$ and HCV mono-infected individuals $(n=15)$ on CD56 ${ }^{+} C D 16^{+/-}$ NK cells. ${ }^{*}, P<0.05 ; n s$ - not significant $(P>0.05)$. In the dot plot figure horizontal line represents \% Mean \pm SEM and Log \% Mean \pm SEM respectively 
CD16 in HIV-HCV co-infected patients also differed significantly as compared to healthy controls and HIV mono-infected group (Fig. 1c).

Our data indicate that HIV-HCV co-infection is associated with an increase of CD56 $6^{\text {bright }}$ NK cells. In addition $\mathrm{CD} 16^{+} \mathrm{CD} 56^{\text {bright }} \mathrm{NK}$ cells in all the infected groups had a significant positive correlation with $\mathrm{CD} 56^{\text {bright }} \mathrm{CD} 16^{+/-} \mathrm{NK}$ cells (Table 1 ).

\section{Expression of NKG2D and NCRs}

The representative flow cytometry plots of NKG2D and NCRs, NKp46 and NKp30 expression on CD56 ${ }^{\text {bright }}$ NK cells is shown in Fig. 2a. All the infected groups did not differ significantly for NKG2D expression on the CD56 $6^{\text {bright }}$ NK cell subset; however its expression was significantly upregulated on all the infected groups as compared to healthy controls (Fig. 2b).

The expression of NKp46 on CD56 ${ }^{\text {bright }}$ NK cells was significantly down-regulated in HIV mono-infected group as compared to healthy controls (Fig. 2c). In contrast, it was up-regulated on HIV-HCV co-infected group as compared to HIV and HCV mono-infected groups. However, the frequency of NKp $46^{+} \mathrm{CD} 56^{\text {bright }} \mathrm{NK}$ cells did not differ significantly between HIV and HCV monoinfections (Fig. 2c).

The log percentage of NKp $30^{+} \mathrm{CD} 56^{\text {bright }}$ NK cells in all the infected groups did not differ significantly as compared to healthy controls. NKp30 expression on CD56 $6^{\text {bright }}$ NK cells was significantly downregulated in HIV mono-infected group than both HIV-HCV coinfection and $\mathrm{HCV}$ mono-infection (Fig. 2d) while in case of HCV mono-infected group NKp30 expression differed significantly as compared to HIV mono-infected group only (Fig. 2d). Also in HIV mono-infected group the expression of NKp46 on CD56 ${ }^{\text {bright }}$ NK cells had a direct correlation with the expression of NKp30 on CD5 $6^{\text {bright }}$ NK cells (Table 1), while in HCV mono-infected patients $\mathrm{NKp} 46^{+} \mathrm{CD} 56^{\text {bright }} \mathrm{NK}$ cells were positively correlated with the expression of CXCR3 on CD56 ${ }^{\text {bright }} \mathrm{NK}$ cells (Table 1 ).

\section{Activation status, expression of Fas receptor (CD95) and proliferative capacity of $\mathrm{CD} 56^{\text {bright }} \mathrm{NK}$ cells}

Figure 3a shows the representative flow cytometry plots of CD69, CD95 and CD127 expressions on CD56 bright $\mathrm{NK}$ cells. The log percentage expression of CD69 which is an early activation marker [22], was found to be considerably increased among CD56 $6^{\text {bright }}$ NK cells in HIV mono-infected and HIV-HCV co-infected groups in comparison to healthy controls suggesting a heightened status of immune activation in HIV mono-infected and HIV-HCV co-infected patients (Fig. 3b). Among the infected groups HIV-HCV coinfected and HCV mono-infected groups showed lower CD69 expression than HIV mono-infected group (Fig. 3b). The finding of a more 'HCV-like' phenotype in HIV-HCV co-infection suggests that reduced CD69 expression might also be caused by an increase of CD56 ${ }^{\text {bright }}$ NK cells that lack CD69 in the HIV-HCV co-infected cohort.

During chronic viral infections, activated immune cells (lymphocytes) or the highly exhausted cells are deleted by apoptosis [23]. CD95 (Fas receptor) binds to CD95L (Fas ligand) and induces apoptosis. The expression of CD95 on CD56 $6^{\text {bright }}$ NK cells was upregulated in both HIV mono-infected and HIV-HCV co-infected groups as compared to healthy controls (Fig. 3c). At the same time, CD95 expression was downregulated on the CD56 ${ }^{\text {bright }}$ NK cell subset in HCV mono-infection in comparison to both HIV mono-infection and HIVHCV co-infection (Fig. 3c).

The expression of CD127 on CD56 ${ }^{\text {bright }}$ NK cells is associated with high proliferative capacity. Expression of

Table 1 Correlation between various NK cell receptors

\begin{tabular}{|c|c|c|c|}
\hline HIV mono-infection & & $\mathrm{CD}^{2} 6^{\text {bright }} \mathrm{CD} 16^{+/-} \mathrm{NK}$ cells & $\mathrm{NKp} 0^{+} \mathrm{CD} 56^{\text {bright }} \mathrm{NK}$ cells \\
\hline \multirow[t]{2}{*}{$\mathrm{CD}_{16}{ }^{+} \mathrm{CD} 56^{\text {bright }} \mathrm{NK}$ cells } & Correlation coefficient & $r_{s}=0.742^{* *}$ & NA \\
\hline & Sig. (2 tailed) & $P<0.01$ & NA \\
\hline \multirow[t]{2}{*}{ NKp $46^{+}$CD $56^{\text {bright }} \mathrm{NK}$ cells } & Correlation coefficient & NA & $r_{s}=0.633^{*}$ \\
\hline & Sig. (2 tailed) & NA & $P<0.05$ \\
\hline HIV-HCV co-infection & & CD56 ${ }^{\text {bright }} \mathrm{CD} 16^{+/-} \mathrm{NK}$ cells & $\mathrm{CD} 127^{+} \mathrm{CD} 56^{\text {bright }} \mathrm{NK}$ cells \\
\hline \multirow[t]{2}{*}{ CD $16^{+}$CD $56^{\text {bright }} \mathrm{NK}$ cells } & Correlation coefficient & $r_{s}=0.810^{* *}$ & NA \\
\hline & Sig. (2 tailed) & $P<0.01$ & NA \\
\hline \multirow[t]{2}{*}{$\mathrm{CD} 9^{+} \mathrm{CD} 56^{\text {bright }} \mathrm{NK}$ cells } & Correlation coefficient & NA & $r_{s}=-0.433^{*}$ \\
\hline & Sig. (2 tailed) & NA & $P<0.05$ \\
\hline HCV mono-infection & & $\mathrm{CXCR3}^{+} \mathrm{CD} 56^{\text {bright }} \mathrm{NK}$ cells & \\
\hline \multirow[t]{2}{*}{ NKp $46^{+}$CD $56^{\text {bright }} \mathrm{NK}$ cells } & Correlation coefficient & $r_{s}=0.587^{*}$ & NA \\
\hline & Sig. (2 tailed) & $P<0.05$ & NA \\
\hline
\end{tabular}

$r_{s}$ Spearman coefficient; NA not applicable; ${ }^{*}, P<0.05 ;{ }^{*}, P<0.01$ 


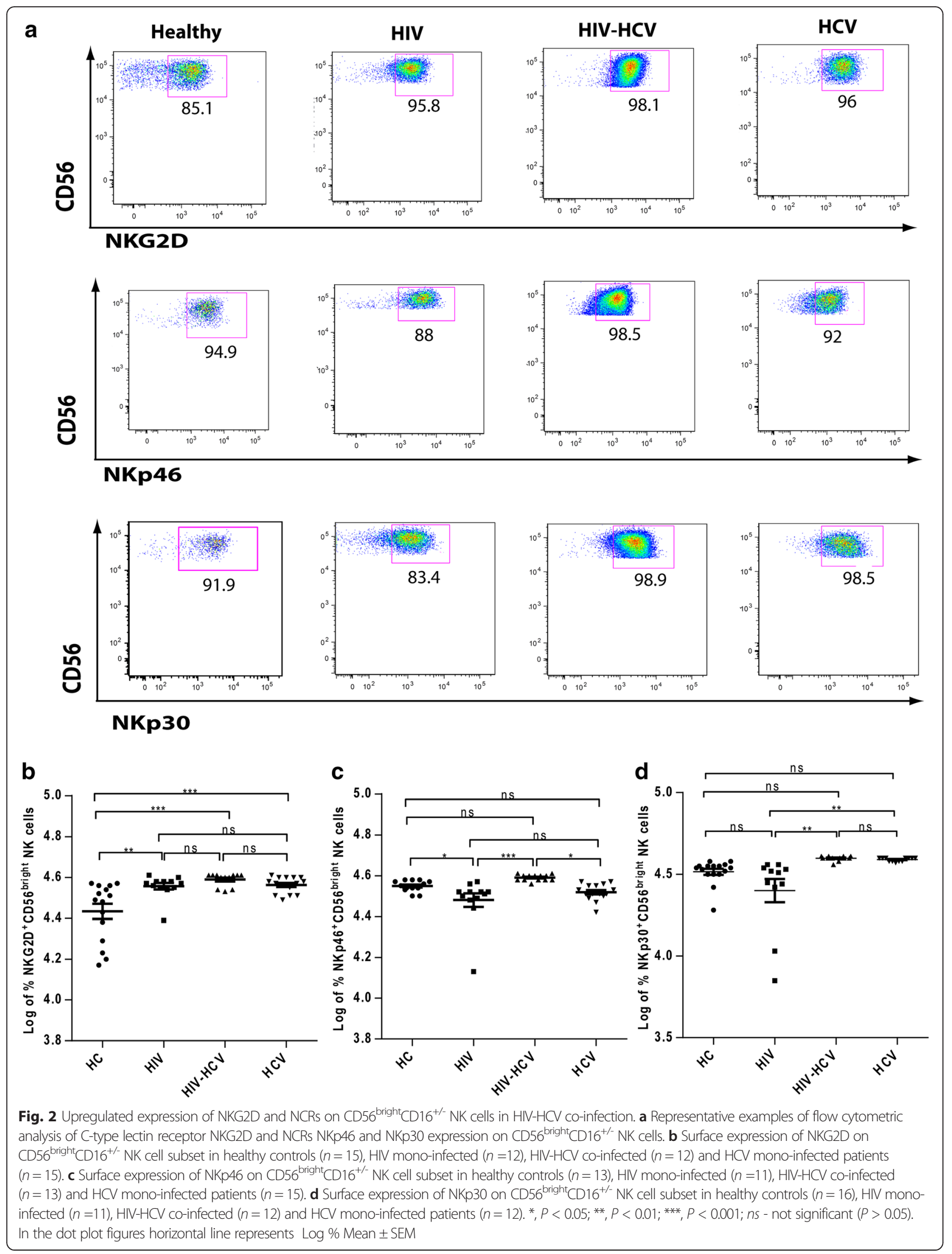




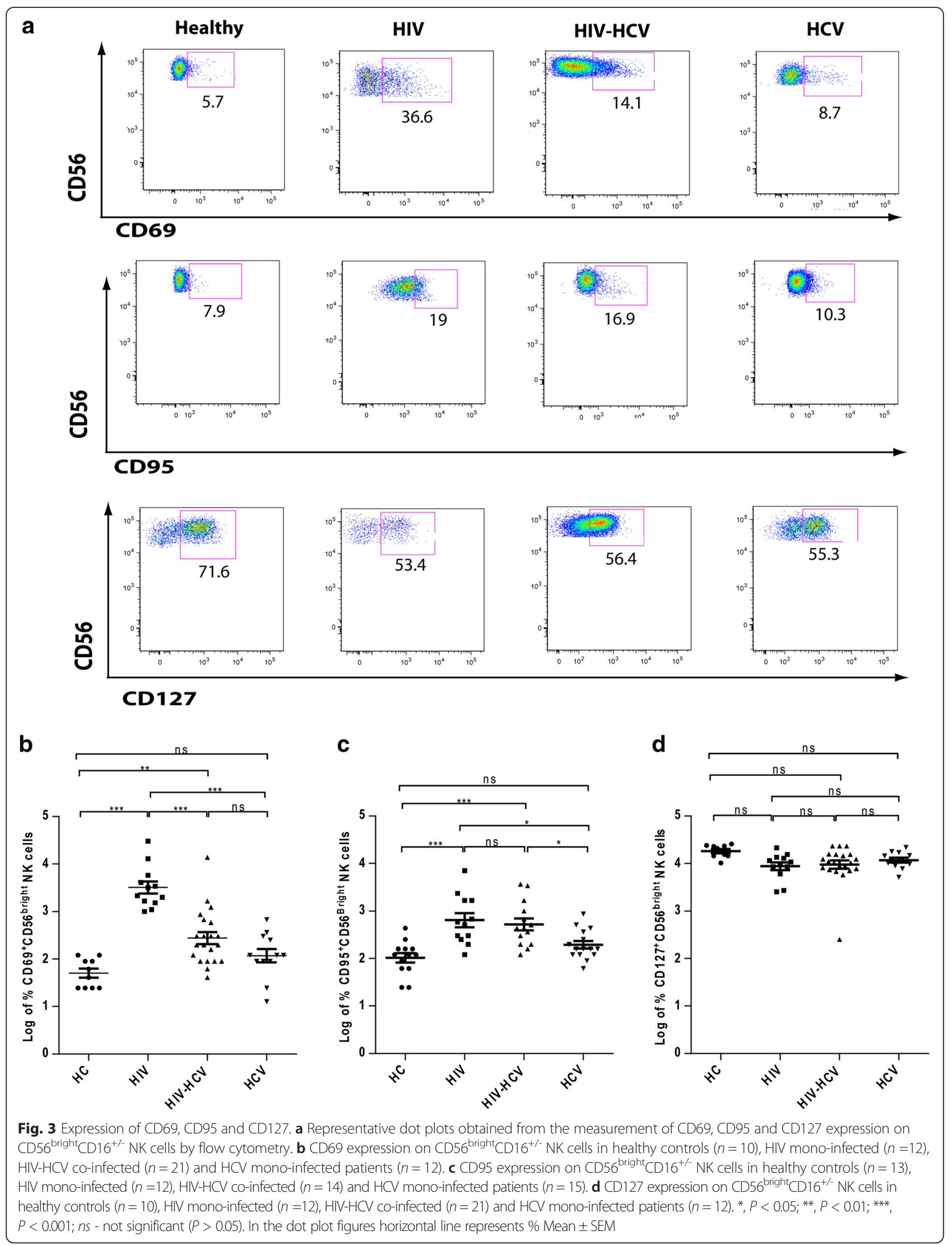


CD127 was downregulated in all the infected groups as compared to healthy controls, although this decrease was not significant (Fig. 3d). Between the infected groups there was no difference for CD127 expression on CD56 ${ }^{\text {bright }} \mathrm{NK}$ cells (Fig. 3d).

In addition, the expression of CD69 on CD56 ${ }^{\text {bright }} \mathrm{NK}$ cells had a negative correlation with $\mathrm{CD} 127^{+} \mathrm{CD} 56^{\text {bright }}$ NK cells (Table 1).

\section{Chemokine receptor CXCR3 expression}

Among the NK cell subsets CXCR3 is expressed more on CD56 ${ }^{\text {bright }}$ than $\mathrm{CD} 56^{\text {dim }}$ subset. As compared to healthy controls, the expression of CXCR3 on CD56 $6^{\text {bright }} \mathrm{NK}$ cells was significantly down-regulated in HIV mono-infected group (Fig. 4b). Interestingly, CXCR3 expression was higher on CD56 ${ }^{\text {bright }} \mathrm{NK}$ cells in the HIV-HCV co-infected group as compared to the HIV mono-infected group (Fig. $4 \mathrm{~b}$ ).

Finally we did not find any correlation between the $\mathrm{HCV}$ or HIV viral load with the fractions of different CD56 ${ }^{\text {bright }}$ NK subsets that were assessed.

\section{Discussion}

HIV-HCV co-infected individuals progress more rapidly to fibrosis, cirrhosis, liver failure and hepatocellular carcinoma than patients infected with HCV alone [7, 24]. Both HIV and HCV mono-infections have been shown to have impaired NK cell functions and skewed subset distributions [7, 9]. However, the impact of HIV-HCV co-infection on phenotypic alterations of NK cell subsets is not well understood. Here, we investigated the phenotype of CD56 ${ }^{\text {bright }}$ NK cells in HIV-HCV co-infected individuals and compared it with HIV or HCV mono infected patients as well as with healthy controls. In our study we found an expansion of CD56 $6^{\text {bright }}$ NK cell subset in HIV-HCV co-infected cohort similar to reported for $\mathrm{HCV}$ mono-infection [25, 26] although there is a study reporting no change in CD56 ${ }^{\text {bright }}$ NK cell compartment in HCV mono-infection [27]. In line with our findings, in a cohort of female patients chronically infected with $\mathrm{HCV}$, the proportion of CD56 $6^{\text {bright }} \mathrm{NK}$ cells was increased as compared to $\mathrm{HCV}$ resolvers and healthy controls [25]. The same increased percentage of CD56 ${ }^{\text {bright }}$ NK cells was found among individuals with a positive tuberculin skin test compared with patients with overt tuberculosis and normal controls [28]. The significance of increased CD56 bright cells in our study is currently unclear. Expansion of CD56 $6^{\text {bright }}$ NK cells in HCV infection might have resulted from a decreased rate of differentiation towards CD56 ${ }^{\mathrm{dim}}$ NK cells in these studies. However, in our study the percentage of total NK cells and CD56 ${ }^{\mathrm{dim}}$ NK cells did not differ among all the groups (data not shown). The increased percentage of CD16 expression on CD56 ${ }^{\text {bright }}$ NK cells in HIV-HCV co-infected patients indicated a phenotypic shift towards CD56 ${ }^{\mathrm{dim}} \mathrm{NK}$ cells and their subsequent role in antibody dependent cellular cytotoxicity (ADCC). Increased expression of CD16 on CD56 ${ }^{\text {bright }}$ NK cells is also reported in HIV-1 infected individuals which is partially restored after ART [29].

NK cell function is primarily regulated by balance between activating and inhibitory receptors. NKG2D and NCRs are one of the main NK cell activating receptors that are required for NK cell effector functions. NKG2D and NCRs are differentially expressed by different subsets of NK cells [20,30]. We analysed the expression of NKG2D and NCRs (NKp30 and NKp46) on CD56 $6^{\text {bright }}$ NK cell subset. NKG2D was upregulated in all the three infected populations as compared to healthy controls. The cytotoxic potential of all NK cell subsets increases when stimulated with cytokines like IL-2 or IL12 in vitro [7]. This might be one of the reasons for the increased expression of NCRs and NKG2D on CD56 $6^{\text {bright }}$ NK cells in vivo as well in chronic viral infections.

In HIV viremic patients, there is an overall decrease of NKp46 and NKp30 on NK cells [14] while in HCV infection couple of studies have shown reduced $\mathrm{NKp} 30^{+} \mathrm{NK}$ cells. In our study, we did not observe a decreased NKp30 expression on CD56 ${ }^{\text {bright }} \mathrm{NK}$ cells in HCV mono-infection. Thus, reduced NKp46 and NKp30 on CD56 ${ }^{\text {bright }}$ NK cells is a unique hallmark of HIV infection [14, 18, 19]. However these results are not directly comparable or necessarily in conflict as our results are focussed on the different fractions of CD56 ${ }^{\text {bright }}$ NK cell subset.

In our study NKp46 expression on HIV-HCV coinfected group differed significantly from both HIV and $\mathrm{HCV}$ mono-infected groups while NKp30 expression was increased on CD56 $6^{\text {bright }}$ NK cell subset in HIV-HCV co-infected cohort which differed significantly as compared to HIV mono-infected group. The finding of increased frequency of NKp30 and NKp46 expressing CD56 ${ }^{\text {bright }}$ NK cells in HIV-HCV co-infection as compared to HIV mono-infection also supports a shift of the populations either due to increased apoptosis of activated CD56 ${ }^{\text {bright }} \mathrm{NK}$ cells or an increase of 'HCV-like' CD56 ${ }^{\text {bright }}$ NK cells in case of NKp30 expression while indicating a unique and an important role of NKp46 in HIV-HCV co-infection.

Immune activation is a hallmark of chronic viral infections like HIV [31]. HIV infected patients showed an increased activation of CD56 $6^{\text {bright }} \mathrm{NK}$ cells as compared to $\mathrm{HIV}-\mathrm{HCV}$ co-infected and $\mathrm{HCV}$ mono-infected groups as measured by the expression of CD69. This might be because of the ongoing residual viral replication even after one year of ART [32]. The reduced expression of CD69 in HIV-HCV co-infected cohort suggests a decreased activation status of CD56 $6^{\text {bright }} \mathrm{NK}$ cells in HIV-HCV co-infection than HIV mono-infection. However, it is unlikely that $\mathrm{HCV}$ co-infection might 'protect' CD56 ${ }^{\text {bright }}$ NK cells from increased immune activation. Alternatively, a loss of CD69 

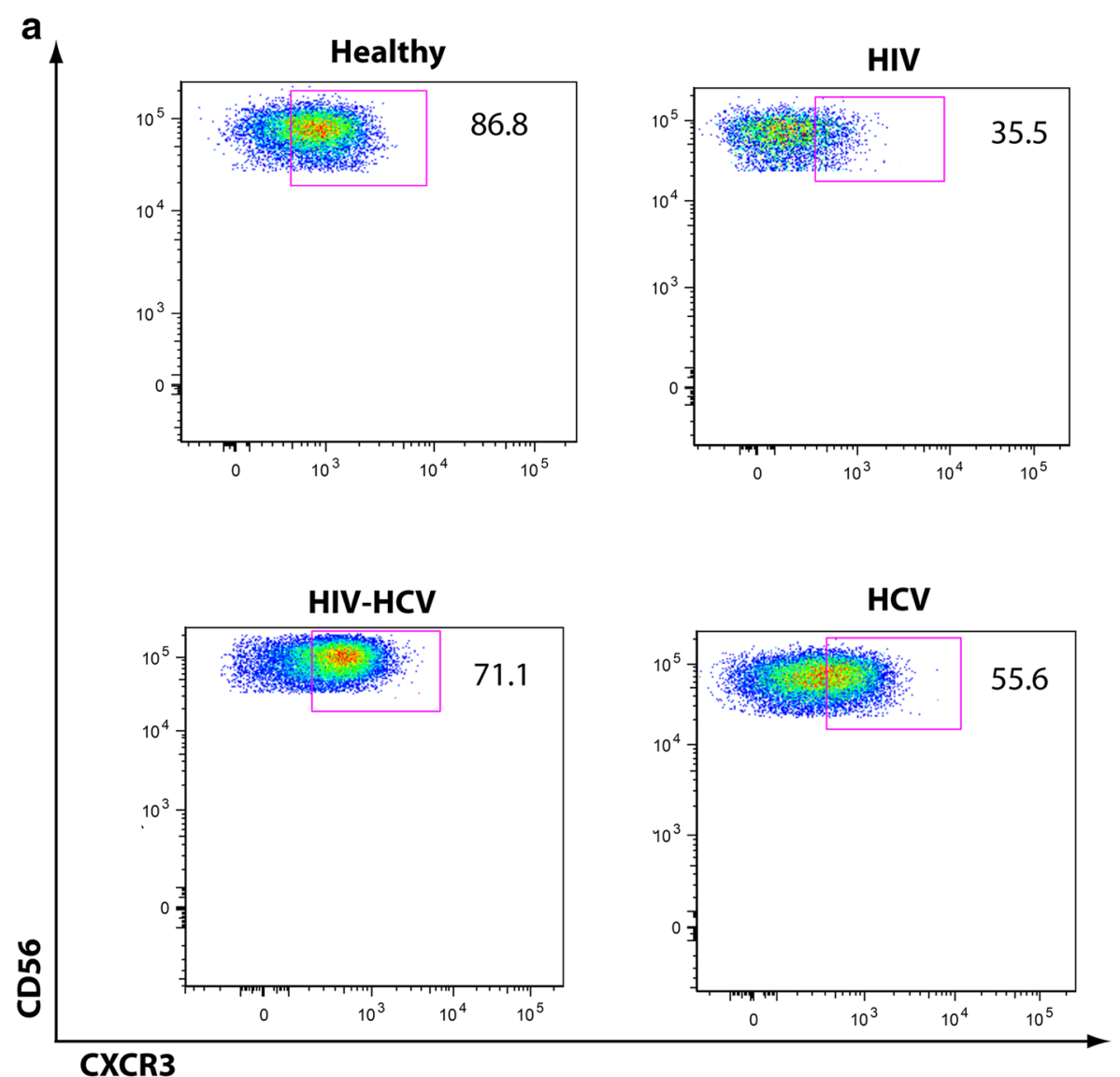

b

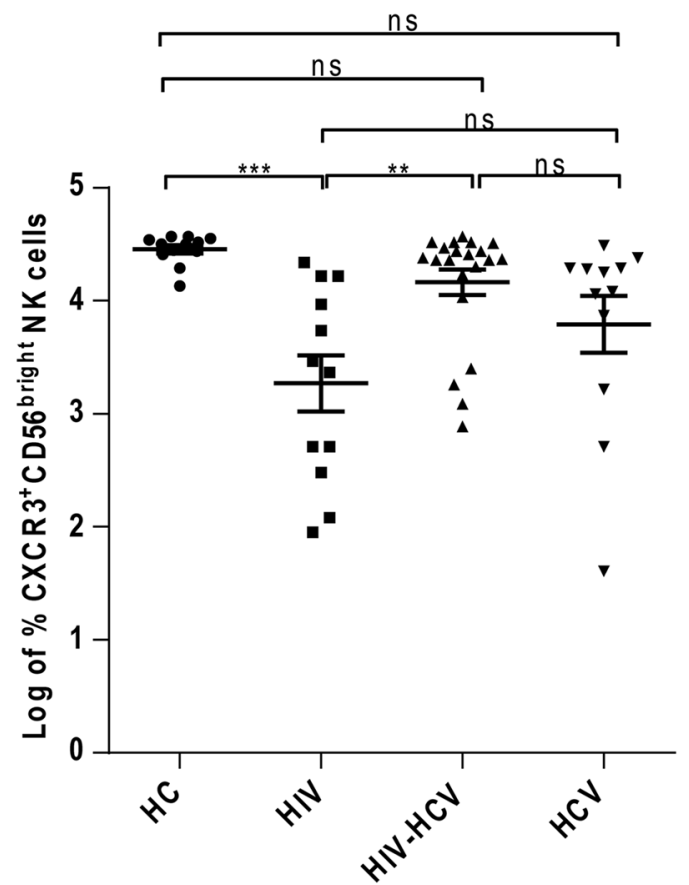

Fig. 4 Increased chemokine receptor CXCR3 expression on CD56 bright $C D 16^{+/-}$NK cells in HIV-HCV co-infection. a Representative dot plots obtained from the measurement of CXCR3 expression on $\mathrm{CD} 56^{\text {bright }} \mathrm{CD} 16^{+-}$NK cells by flow cytometry. $\mathbf{b}$ CXCR3 expression on $\mathrm{CD} 56^{\text {bright }} \mathrm{CD} 16^{+/-} \mathrm{NK}$ cells in healthy controls $(n=10)$, HIV mono-infected $(n=12)$, HIV-HCV co-infected $(n=21)$ and HCV mono-infected patients $(n=12)$. ${ }^{* *}, P<0.01$; ${ }^{* * *}, P<0.001$; $n s$ - not significant $(P>0.05)$. In the dot plot figure horizontal line represents Log \% Mean \pm SEM 
expressing CD56 ${ }^{\text {bright }}$ NK cells could be either due to increased apoptosis or a relative increase of CD69 negative NK cells in the HIV-HCV co-infected cohort or both. We therefore analysed the expression of the apoptosis marker CD95.

Immune cells undergo apoptosis as a result of chronic activation or exhaustion during chronic viral infections. Fas mediated apoptosis (FMA) is one of the mechanisms by which cells undergo apoptosis [33]. The expression of Fas receptor CD95 on CD56 ${ }^{\text {bright }}$ NK subset was higher in HIV mono-infected patients. The same group also had the high expression of CD69 on the CD56 ${ }^{\text {bright }}$ NK cells showing a chronic systemic immune activation status. The increased expression of CD69 as well as CD95 on CD56 bright NK cell subset in HIV treated patients may render activated NK cells more prone to undergo apoptosis. Enhanced susceptibility of NK cells to cell death by CD95-CD95L in HIV infected viremic individuals has already been reported by Kottilil et al. [34]. A number of reports show increased expression of CD95 on various lymphocyte subsets as a result of immune activation induced by HIV viremia thereby facilitating lymphocyte apoptosis $[35,36]$. The expression of CD69 on CD56 $6^{\text {bright }} \mathrm{NK}$ cells in HIV-HCV co-infected group was closer to HCV mono-infected group whereas the CD95 expression behaved more similar to HIV treated mono-infected group thus showing imprints of either infection.

CD127 (IL-7R $\alpha$ receptor) is important for homeostatic proliferation, particularly in lymphopenic settings when remaining cells initiate a homeostatic response to repopulate the depleted compartment. The level of IL-7 and expression patterns of CD127 are believed to be skewed in HIV [37, 38]. Our study also demonstrated a skewed expression of $\mathrm{CD} 127$ on CD56 $6^{\text {bright }} \mathrm{NK}$ cells in all the infected groups as compared to healthy controls, but the difference was not significant. Chronic viral infections may be associated with reduced $\mathrm{CD} 127$ in general.

Chemokine receptor CXCR3 and its ligands (particularly IP-10) are associated with a type 1 response and recruit lymphocytes to the liver [39, 40]. Kimball et al. [41] have previously demonstrated an increased CXCR3 expression on $\mathrm{CD}^{+} \mathrm{T}$ cells from HIV-HCV co-infected patients as compared to healthy controls. A recent study showed $\mathrm{HCV}$ infection to be associated with significantly increased frequency of $\mathrm{CXCR}^{+}{ }^{+} \mathrm{CD} 56^{\text {bright }} \mathrm{NK}$ cells but these cells showed an impaired degranulation and IFN- $\gamma$ secretion in response to hepatic stellate cells (HSCs) [42]. In our study, we observed a decreased expression of the frequency of $\mathrm{CXCR}^{+}{ }^{+} \mathrm{CD} 56^{\text {bright }} \mathrm{NK}$ cells in $\mathrm{HCV}$ monoinfection as well as in HIV mono-infection, which was even more pronounced than in $\mathrm{HCV}$ mono-infection. In addition, our study showed an elevated expression of CXCR3 on CD56 ${ }^{\text {bright }}$ NK cells in HIV-HCV co-infection as compared to HIV and HCV mono-infected groups which may reflect an effort to recruit more CD56 ${ }^{\text {bright }}$ NK cells to liver in the wake of a co-infection.

One of the limitations of the current study is the lack of NK cell functional data in terms of NK cell cytotoxicity and cytokine secretion. Functional assays will reflect more clearly on the real impact of HIV or HCV mono-infection on HIV-HCV co-infection and may also help in deciphering the complex phenotype observed in HIV-HCV co-infection in our study.

In summary, the increased CD56 $6^{\text {bright }}$ NK cells in HIV$\mathrm{HCV}$ co-infection might be a compensatory mechanism to recruit more immunoregulatory CD56 ${ }^{\text {bright }}$ NK cells. Even though NKp30 and NKp40 expression was increased in HIV-HCV co-infection, NKp40 expression was unique for HIV-HCV co-infection as it behaved neither like HIV nor HCV mono-infection. This observation may imply that among NCRs, NKp46 seems to play an important role in the cytotoxic potential of CD56 $6^{\text {bright }} \mathrm{NK}$ cells and in combating both HIV and HCV mono-infections. NKp30 expression was same for $\mathrm{HCV}$ mono-infection and HIV-HCV co-infection indicating that chronic viral hepatic infections do not have a dominant bearing on the expression of NKp30 on CD56 $6^{\text {bright }}$ NK cells. While HIV and HCV mono-infections differed for NKp30 expression, they remained same for NKp46 expression on CD56 ${ }^{\text {bright }} \mathrm{NK}$ cells. Increased NKG2D expression in HIV and HCV mono-infections and HIV-HCV co-infection rather reflects a general feature of viral infections. Interestingly, CXCR3 expression increased in HIV-HCV co-infection vis-à-vis in HIV and HCV mono-infections - probably caused by an additional infection. It can also be speculated that increased CD69 and CD95 expression on CD56 ${ }^{\text {bright }}$ NK cells in HIV mono-infection are a reflection of their exhaustive phenotype. A summary of various NK cell receptors expression is provided in Table 2 .

\section{Conclusion}

HIV-HCV co-infection exhibits a complex imprinting of the CD56 ${ }^{\text {bright }}$ NK cell phenotype. HIV-HCV co-infection is characterized by an increased CD56 $6^{\text {bright }} \mathrm{NK}$ cell population. NKG2D expression behaves similarily in all the infected groups. NKp46 expression is higher in HIV-HCV co-infection than in both mono-infections and is thus distinct for HIV-HCV co-infection, while NKp30 expression behaves more like in $\mathrm{HCV}$ mono-infection. The expression of the activation marker CD69 and FasR CD95 is in between HIV and HCV mono-infections (closer to $\mathrm{HCV}$ mono-infection and closer to HIV mono-infection respectively) but clearly influenced by both HIV and HCV mono-infections for CD69 and CD95 expressions. CD127 expression is same in all the groups. Expression of CXCR3 in co-infection is clearly different as it is not reduced as much as in either mono-infections so this combination is also unique for HIV-HCV co-infection. 
Table 2 Summary of various NK cell receptors expression data

\begin{tabular}{|c|c|c|c|c|c|c|}
\hline NK cell receptor & HIV vs HC & HIV-HCV vs HC & $\mathrm{HCV}$ vs HC & HIV-HCV vs HIV & HIV-HCV vs HCV & HIV vs HCV \\
\hline CD56 bright NK cells & - & $\uparrow$ & - & $\uparrow$ & - & - \\
\hline CD $16^{+}$CD56 bright $\mathrm{NK}$ cells & - & $\uparrow \uparrow \uparrow$ & - & $\uparrow \uparrow \uparrow$ & $\uparrow \uparrow$ & - \\
\hline NKG2D ${ }^{+}$CD56 bright $N K$ cells & $\uparrow \uparrow$ & $\uparrow \uparrow \uparrow$ & $\uparrow \uparrow \uparrow$ & - & - & - \\
\hline NKp46 ${ }^{+}$CD56 bright $N K$ cells & $\downarrow$ & - & - & $\uparrow \uparrow \uparrow$ & $\uparrow$ & - \\
\hline $\mathrm{NKp} 30^{+} \mathrm{CD} 56^{\text {bright }} \mathrm{NK}$ cells & - & - & - & $\uparrow \uparrow$ & - & $\downarrow \downarrow$ \\
\hline CD69+CD56 bright $N K$ cells & $\uparrow \uparrow \uparrow$ & $\uparrow \uparrow$ & - & $\downarrow \downarrow \downarrow$ & - & $\uparrow \uparrow \uparrow$ \\
\hline $\mathrm{CD} 5^{+} \mathrm{CD} 56^{\text {bright }} \mathrm{NK}$ cells & $\uparrow \uparrow \uparrow$ & $\uparrow \uparrow \uparrow$ & - & - & $\uparrow$ & $\uparrow$ \\
\hline $\mathrm{CD} 127^{+} \mathrm{CD} 56^{\text {bright }} \mathrm{NK}$ cells & - & - & - & - & - & - \\
\hline $\mathrm{CXCR}^{+}{ }^{+} \mathrm{CD} 56^{\text {bright }} \mathrm{NK}$ cells & $\uparrow \uparrow \uparrow$ & - & - & $\uparrow \uparrow$ & - & - \\
\hline
\end{tabular}

Direction of the arrows documents upregulation or downregulation of NK receptor expression in respective comparisons. $\uparrow$ or $\downarrow=P<0.05$; $\uparrow \uparrow$ or $\downarrow \downarrow=P<0.01 ; \uparrow \uparrow \uparrow$ or $\downarrow \downarrow \downarrow=P<0.001$

Thus we see a complex phenotype of CD56 $6^{\text {bright }}$ NK cells in HIV-HCV co-infection. Future functional studies may investigate as to what extend these altered phenotypes may influence the course of co-infection and which factors are responsible for each individual to define how HIV-HCV co-infection affects the CD56 $6^{\text {bright }}$ NK cells.

\section{Methods}

\section{Study subjects}

We obtained peripheral blood samples from 12 HIV seropositive subjects both treated [11] and untreated [1], 15 HCV mono-infected untreated subjects with replicative $\mathrm{HCV}$ infection, $21 \mathrm{HIV}-\mathrm{HCV}$ co-infected subjects both treated [17] and untreated [4] for HIV in the HIV outpatient clinic of the Medizinische Hochschule Hannover
(MHH) but treatment naïve for HCV and 16 healthy controls. All HCV infected subjects were also treatment naive for hepatitis $\mathrm{C}$ during the study period. All study subjects were recruited at the HIV and HCV outpatient clinic of the Medizinische Hochschule Hannover $(\mathrm{MHH})$ and of the University Medical Centre, Hamburg-Eppendorf. All study participants gave written, informed consent prior to their participation. The study was approved by the local ethics committee (Votum der Ethikkommission der MHH No. 3150).

A summary of the demographical data of the studied groups is shown in Table 3. Plasma HIV-1 RNA level was measured with the COBAS TaqMan HIV-1 test (Roche Diagnostics, Basel, Switzerland) with a lower limit of detection of 34 copies $/ \mathrm{ml}$.

Table 3 Summary and comparison of log values of demographic characteristics of study groups

\begin{tabular}{|c|c|c|c|c|c|}
\hline Parameters & $\begin{array}{l}\mathrm{HC} \\
(n=16)\end{array}$ & $\begin{array}{l}\text { HIV } \\
(n=12)\end{array}$ & $\begin{array}{l}\text { HIV-HCV } \\
(n=21)\end{array}$ & $\begin{array}{l}\mathrm{HCV} \\
(n=15)\end{array}$ & $P$ value \\
\hline Mean age (years) $\pm S D$ & $43.8 \pm 3.3$ & $45 \pm 5.5$ & $47 \pm 7.6$ & $48.5 \pm 5.8$ & 0.15 \\
\hline Male/Female & $7 / 5$ & $8 / 4$ & $16 / 5$ & $7 / 8$ & 0.34 \\
\hline HIV RNA, mean copies/ml & Seronegative & $6.1 \pm 3.5$ & $5.7 \pm 3.0$ & N/A & 0.76 \\
\hline Mean $\mathrm{CD}^{+} \mathrm{T}$ cell count $(\mathrm{n} / \mu \mathrm{l}) \pm \mathrm{SD}$ & NT & $6.1 \pm 0.5$ & $5.8 \pm 0.7$ & NT & 0.24 \\
\hline Treated/Untreated for HIV & N/A & $11 / 1$ & $17 / 4$ & N/A & 0.41 \\
\hline \multirow[t]{2}{*}{ HCV RNA, mean copies/ml } & Seronegative & N/A & $13.0 \pm 2.9$ & $14.5 \pm 1.1$ & 0.12 \\
\hline & & & & $n=4(\mathrm{NA})$ & \\
\hline \multirow[t]{2}{*}{ AST $(U / L)$, mean } & & & $4.2 \pm 0.5$ & $3.9 \pm 0.5$ & 0.1 \\
\hline & NT & N/A & $n=2(\mathrm{NA})$ & $n=1(\mathrm{NA})$ & \\
\hline \multirow[t]{2}{*}{$\operatorname{ALT}(U / L)$, mean } & & & $4.2 \pm 0.7$ & $4.0 \pm 0.7$ & 0.36 \\
\hline & NT & N/A & $n=2(N A)$ & $n=1(\mathrm{NA})$ & \\
\hline \multirow[t]{2}{*}{ үGT $(U / L)$, mean } & & & $4.4 \pm 0.8$ & $4.0 \pm 0.8$ & 0.15 \\
\hline & NT & N/A & $n=2(\mathrm{NA})$ & $n=1(\mathrm{NA})$ & \\
\hline \multirow[t]{2}{*}{ Billirubin $(\mu \mathrm{mol} / \mathrm{L})$, mean } & & & $2.3 \pm 0.6$ & $2.4 \pm 0.4$ & 0.72 \\
\hline & NT & N/A & $n=2(\mathrm{NA})$ & $n=1(\mathrm{NA})$ & \\
\hline
\end{tabular}


Absolute counts of $\mathrm{CD} 4^{+} \mathrm{T}$ cells, NK cells and other lymphocyte subpopulations were determined by flow cytometry using a cocktail of antibodies from Beckman Coulter, California, USA either directed against CD45, CD3, CD4 and CD8 or CD45, CD56, CD19, CD3 and CD16.

\section{Isolation of mononuclear cells}

PBMCs were isolated from fresh blood as described previously [17]. Aliquots of $10^{7}$ PBMCs each were cryopreserved in heat-inactivated FCS supplemented with 10 $\%$ dimethyl sulfoxide (DMSO) (Merck, NJ, USA).

\section{Phenotypic analysis of NK cells by flowcytometry}

Staining and flow cytometric analysis was performed as described before [10]. The Following monoclonal antibodies were used in this study: Via probe PerCP, anti-CD19 PerCP, anti-CD14 PerCP and anti-CD3 PerCP (BD Biosciences, CA, USA) to exclude dead cells, B cells, monocytes and T cells, respectively, and anti-CD56 PC7 (Beckman Coulter, CA, USA) and anti-CD16 APC-H7 (BD Biosciences, CA, USA) to identify NK cells. Additional antibodies that were used include: anti-CXCR3 APC (BD Biosciences, CA, USA), antiCD69 PE (Invitrogen, CA, USA), anti-CD127 PacBlue (BD Biosciences, CA, USA), anti-CD95 APC (Biolegend, CA, USA), anti-NKp30 APC (Beckman Coulter, CA, USA), antiNKp46 PE (Beckman Coulter, CA, USA), anti-NKG2D APC (BD Biosciences, CA, USA). At least 1 million events were acquired for each sample, using the BD Canto II (BD Biosciences, CA, USA). Data were analysed with FlowJo 8.8.4 (TreeStar, Or, USA). Lymphocytes were defined by forward and side scatter. $\mathrm{CD}^{+}, \mathrm{CD} 14^{+}, \mathrm{CD} 19^{+}$, dead cells and cell aggregates were removed from analysis based on PerCP and Viaprobe cell viability staining and pulse width analysis. Fluorescence minus one (FMO) staining was used to determine threshold values for the expression of each surface marker.

\section{Statistical analysis}

GraphPad Prism (version 5.0) software was used for statistical evaluation of the data. One-way ANOVA followed by post hoc comparison by Bonferroni method was performed. Kruskal-Wallis test was applied for $\mathrm{CD} 16^{+} \mathrm{CD} 56^{\text {bright }} \mathrm{NK}$ cells followed by multiple comparisons by Mann-Whitney after adjusting the probability level. The correlation between various parameters was studied using Pearson/ Spearman correlation. The categorical data was analysed by chi-square/Fisher's exact test wherever necessary. The log transformation was also applied for making the skewed data normalized. $P$ values less than 0.05 were considered significant.

\section{Competing interests}

The authors declare that they have no competing interests.

\section{Authors' contributions}

$\mathrm{SB}$ and $\mathrm{DMO}$ conceived the study and $\mathrm{SB}, \mathrm{FA}$ and $\mathrm{DMO}$ designed the experiments. SB and FA performed the experiments. HW, MC, JSzW, JVL provided the HCV infected samples. SB, FA, DMO analysed the data. SB wrote the manuscript. DMO, RES, SKS, HW, MC, JSzW, JVL and FA critically revised the manuscript. All authors read and commented on the manuscript.

\section{Acknowledgments}

This work was supported by grants from the Bundesministerium für Bildung und Forschung, Stiftung Zukunfts- und Innovations fonds Niedersachsen and

Helmholtz-Zentrum für Infektions forschung (IG-SCID-TwinPro02 to D.M.O.), DZIF TTU 04.802 (R.E.S. JVL, JSzW and D.M.O.), the MD/PhD program of the Hannover Biomedical Research School (F.A.) and 5/8/7/9/2007(A)-ECD-I under Indian Council of Medical Research (India) -HGF (Helmholtz Association, Germany). S.B. received Research Associate fellowship from ICMR and F.A. received postdoctoral fellowship from DZIF TTU 04.802. SZW got funding from the German Research Agency SFB 841 A6.

Data previously presented at $8^{\text {th }}$ International symposium on Alcoholic Liver and Pancreatic Diseases and Cirrhosis, New Delhi, India, November 15-17,

2013 and published as abstract no. 34.

\section{Author details}

${ }^{1}$ Institute of Liver and Billiary Sciences, New Delhi, India. ${ }^{2}$ Klinik für Immunologie und Rheumatologie, Medizinische Hochschule Hannover, Hannover, Germany. ${ }^{3}$ Klinik für Gasteroenterologie, Hepatologie und Endokrinologie, Medizinische Hochschule Hannover, Hannover, Germany. ${ }^{4}$ Department of Medicine, University Medical Center, Hamburg-Eppendorf, Germany. ${ }^{5}$ Rheumatology and Internal Medicine, $m$ \& i-Fachklinik Bad Pyrmont, Bad Pyrmont, Germany. ${ }^{6}$ Viiv healthcare, London, UK. ${ }^{7}$ German Center for Infection Research (DZIF), Hamburg, Hannover, Germany.

Received: 15 July 2015 Accepted: 14 March 2016

Published online: 18 April 2016

\section{References}

1. Caligiuri MA. Human natural killer cells. Blood. 2008;112(3):461-9.

2. Vivier E, Raulet $D H$, Moretta $A$, Caligiuri MA, Zitvogel L, Lanier LL, et al. Innate or adaptive immunity? The example of natural killer cells. Science. 2011;331(6013):44-9.

3. Fauci AS, Mavilio D, Kottilil S. NK cells in HIV infection: paradigm for protection or targets for ambush. Nat Rev Immunol. 2005;5(11):835-43.

4. Poli A, Michel T, Theresine M, Andres E, Hentges F, Zimmer J. CD56bright natural killer (NK) cells: an important NK cell subset. Immunology. 2009;126(4):458-65.

5. Campbell JJ, Qin S, Unutmaz D, Soler D, Murphy KE, Hodge MR, et al. Unique subpopulations of CD56+ NK and NK-T peripheral blood lymphocytes identified by chemokine receptor expression repertoire. J Immunol. 2001;166(11):6477-82.

6. Fauriat $\mathrm{C}$, Long $\mathrm{EO}$, Ljunggren $\mathrm{HG}$, Bryceson $\mathrm{YT}$. Regulation of human NK-cell cytokine and chemokine production by target cell recognition. Blood. 2010; 115(11):2167-76.

7. Cooper MA, Fehniger TA, Turner SC, Chen KS, Ghaheri BA, Ghayur T, et al. Human natural killer cells: a unique innate immunoregulatory role for the CD56(bright) subset. Blood. 2001;97(10):3146-51.

8. Mohsen AH, Easterbrook P, Taylor CB, Norris S. Hepatitis C and HIV-1 coinfection. Gut. 2002;51(4):601-8.

9. Azzoni L, Papasavvas E, Chehimi J, Kostman JR, Mounzer K, Ondercin J, et al. Sustained impairment of IFN-gamma secretion in suppressed HIV-infected patients despite mature NK cell recovery: evidence for a defective reconstitution of innate immunity. J Immunol. 2002;168(11):5764-70.

10. Hong HS, Eberhard JM, Keudel P, Bollmann BA, Ballmaier M, Bhatnagar N, et al. HIV infection is associated with a preferential decline in less-differentiated CD56 ${ }^{\text {dim }}$ CD16 ${ }^{+}$NK cells. J Virol. 2010;84(2):1183-8.

11. Varchetta S, Mele D, Mantovani S, Oliviero B, Cremonesi E, Ludovisi S, et al. Impaired intrahepatic natural killer cell cytotoxic function in chronic hepatitis C virus infection. Hepatology. 2012;56(3):841-9.

12. Ahlenstiel G, Edlich B, Hogdal L, Rotman Y, Noureddin M, Feld JJ, et al. Early changes in natural killer cell function indicate virologic response to interferon therapy for hepatitis C. Gastroenterology. 2011;141(4):1231-9. 9 e1-2.

13. Ahmad F, Hong HS, Jackel M, Jablonka A, Lu IN, Bhatnagar N, et al. High frequencies of polyfunctional $\mathrm{CD}^{+}{ }^{+} \mathrm{NK}$ cells in chronic HIV-1 infection are associated with slower disease progression. J Virol. 2014;88(21):12397-408. 
14. De Maria A, Fogli M, Costa P, Murdaca G, Puppo F, Mavilio D, et al. The impaired NK cell cytolytic function in viremic HIV-1 infection is associated with a reduced surface expression of natural cytotoxicity receptors (NKp46, NKp30 and NKp44). Eur J Immunol. 2003;33(9):2410-8.

15. Mantegani P, Tambussi G, Galli L, Din CT, Lazzarin A, Fortis C. Perturbation of the natural killer cell compartment during primary human immunodeficiency virus 1 infection primarily involving the CD56 bright subset. Immunology. 2010;129(2):220-33.

16. De Maria A, Fogli M, Mazza S, Basso M, Picciotto A, Costa P, et al. Increased natural cytotoxicity receptor expression and relevant IL-10 production in NK cells from chronically infected viremic HCV patients. Eur J Immunol. 2007;37(2):445-55.

17. Meyer-Olson D, Brady KW, Bartman MT, O'Sullivan KM, Simons BC, Conrad JA, et al. Fluctuations of functionally distinct CD8+ T-cell clonotypes demonstrate flexibility of the HIV-specific TCR repertoire. Blood. 2006;107(6):2373-83.

18. Holder KA, Stapleton SN, Gallant ME, Russell RS, Grant MD. Hepatitis C virusinfected cells downregulate NKp30 and inhibit ex vivo NK cell functions. J Immunol. 2013;191(6):3308-18.

19. Mantovani S, Mele D, Oliviero B, Barbarini G, Varchetta S, Mondelli MU. NKp30 isoforms in patients with chronic hepatitis $C$ virus infection. Immunology. 2015;146(2):234-42.

20. Bauer S, Groh V, Wu J, Steinle A, Phillips JH, Lanier LL, et al. Activation of NK cells and T cells by NKG2D, a receptor for stress-inducible MICA. Science. 1999;285(5428):727-9.

21. Ahlenstiel G, Titerence RH, Koh C, Edlich B, Feld JJ, Rotman Y, et al. Natural killer cells are polarized toward cytotoxicity in chronic hepatitis $C$ in an interferon-alfa-dependent manner. Gastroenterology. 2010;138(1):325-35. e1-2.

22. Clausen J, Vergeiner B, Enk M, Petzer AL, Gastl G, Gunsilius E. Functional significance of the activation-associated receptors CD25 and CD69 on human NK-cells and NK-like T-cells. Immunobiology. 2003;207(2):85-93.

23. Wherry EJ, Blattman JN, Murali-Krishna K, van der Most R, Ahmed R. Viral persistence alters CD8 T-cell immunodominance and tissue distribution and results in distinct stages of functional impairment. J Virol. 2003;77(8):4911-27.

24. Bica I, McGovern B, Dhar R, Stone D, McGowan K, Scheib R, et al. Increasing mortality due to end-stage liver disease in patients with human immunodeficiency virus infection. Clin Infect Dis. 2001;32(3):492-7.

25. Golden-Mason L, Madrigal-Estebas L, McGrath E, Conroy MJ, Ryan EJ, Hegarty JE, et al. Altered natural killer cell subset distributions in resolved and persistent hepatitis $C$ virus infection following single source exposure. Gut. 2008;57(8):1121-8.

26. Lee $S$, Watson MW, Flexman JP, Cheng W, Hammond T, Price P. Increased proportion of the CD56(bright) NK cell subset in patients chronically infected with hepatitis $\mathrm{C}$ virus ( $\mathrm{HCV}$ ) receiving interferonalpha and ribavirin therapy. J Med Virol. 2010;82(4):568-74.

27. Miyagi T, Shimizu S, Tatsumi T, Nishio K, Hiramatsu N, Kanto T, et al. Differential alteration of CD56(bright) and CD56 (dim) natural killer cells in frequency, phenotype, and cytokine response in chronic hepatitis $C$ virus infection. J Gastroenterol. 2011;46(8):1020-30.

28. Barcelos W, Sathler-Avelar R, Martins-Filho OA, Carvalho BN, Guimaraes TM, Miranda SS, et al. Natural killer cell subpopulations in putative resistant individuals and patients with active Mycobacterium tuberculosis infection. Scand J Immunol. 2008;68(1):92-102.

29. Hong HS, Ahmad F, Eberhard JM, Bhatnagar N, Bollmann BA, Keudel P, et al. Loss of CCR7 expression on CD56 $6^{\text {(bright) }}$ NK cells is associated with a CD56 ${ }^{\text {(dim) }}$ CD $16^{(+)}$NK cell-like phenotype and correlates with HIV viral load. PLoS One. 2012;7(9):e44820.

30. Marras F, Bozzano F, De Maria A. Involvement of activating NK cell receptors and their modulation in pathogen immunity. J Biomed Biotechnol. 2011 2011:152430.

31. Brenchley JM, Price DA, Schacker TW, Asher TE, Silvestri G, Rao S, et al. Microbial translocation is a cause of systemic immune activation in chronic HIV infection. Nat Med. 2006:12(12):1365-71.

32. Ahmad F, Tufa DM, Mishra N, Jacobs R, Schmidt RE. Terminal differentiation of $\mathrm{CD}^{2} 6^{\mathrm{dim}} \mathrm{CD} 16^{+}$natural killer cells is associated with increase in natural killer cell frequencies after antiretroviral treatment in HIV-1 infection. AIDS Res Hum Retroviruses. 2015;31(12):1206-12.

33. Poonia B, Pauza CD, Salvato MS. Role of the Fas/FasL pathway in HIV or SIV disease. Retrovirology. 2009;6:91.

34. Kottilil S, Jackson JO, Reitano KN, O'Shea MA, Roby G, Lloyd M, et al. Innate immunity in HIV infection: enhanced susceptibility to CD95-mediated natural killer cell death and turnover induced by HIV viremia. J Acquir Immune Defic Syndr. 2007:46(2):151-9.

35. Wasmuth JC, Klein KH, Hackbarth F, Rockstroh JK, Sauerbruch T, Spengler U. Prediction of imminent complications in HIV-1-infected patients by markers of lymphocyte apoptosis. J Acquir Immune Defic Syndr. 2000;23(1):44-51.

36. Vigano A, Pinti M, Nasi M, Moretti L, Balli F, Mussini C, et al. Markers of cell death-activation in lymphocytes of vertically HIV-infected children naive to highly active antiretroviral therapy: the role of age. J Allergy Clin Immunol. 2001;108(3):439-45

37. Read SW, Higgins J, Metcalf JA, Stevens RA, Rupert A, Nason MC, et al. Decreased CD127 expression on T Cells in HIV-1-infected adults receiving antiretroviral therapy with or without intermittent IL-2 therapy. J Acquir Immune Defic Syndr. 2006;42(5):537-44.

38. Mojumdar K, Vajpayee M, Chauhan NK, Singh A, Singh R, Kurapati S. Loss of CD127 \& increased immunosenescence of T cell subsets in HIV infected individuals. Indian J Med Res. 2011;134(6):972-81.

39. Larrubia JR, Benito-Martinez S, Calvino M, Sanz-de-Villalobos E, Parra-Cid T. Role of chemokines and their receptors in viral persistence and liver damage during chronic hepatitis C virus infection. World J Gastroenterol. 2008:14(47):7149-59.

40. Zeremski M, Petrovic LM, Talal AH. The role of chemokines as inflammatory mediators in chronic hepatitis C virus infection. J Viral Hepat. 2007;14(10):675-87.

41. Kimball P, MCDougan F, Stirling R. CXCR3 expression elevated on peripheral CD8(+) lymphocytes from HIV/HCV coinfected individuals. Viral Immunol. 2011;24(6):441-8.

42. Eisenhardt M, Glassner A, Kramer B, Korner C, Sibbing B, Kokordelis P, et al. The CXCR3(+)CD56Bright phenotype characterizes a distinct NK cell subset with anti-fibrotic potential that shows dys-regulated activity in hepatitis C. PLoS One. 2012;7(7):e38846.

\section{Submit your next manuscript to BioMed Central and we will help you at every step:}

- We accept pre-submission inquiries

- Our selector tool helps you to find the most relevant journal

- We provide round the clock customer support

- Convenient online submission

- Thorough peer review

- Inclusion in PubMed and all major indexing services

- Maximum visibility for your research

Submit your manuscript at www.biomedcentral.com/submit
) Biomed Central 